\title{
ВЕТРОЭНЕРГЕТИЧЕСКИЕ РЕСУРСЫ ЦЕНТРАЛЬНЫХ РАЙОНОВ РЕСПУБЛИКИ АЛТАЙ
}

\author{
Севастьянов Владимир Вениаминович', \\ vvs187@mail.ru
}

\author{
Сапьян Екатерина Сергеевна', \\ Katerinass@vtomske.ru \\ 1 Национальный исследовательский Томский государственный университет, \\ Россия, 634050, Томск, пр. Ленина, 36.
}

\begin{abstract}
Актуальность исследования. Среди наиболее острых проблем, волнующих человечество, следует выделить энергетические проблемы. Они влияют непосредственно или опосредованно на человека, общество и окружающую среду. Человеческая деятельность связана с беспрерывным использованием природных энергоресурсов для обеспечения своей жизнедеятельности: теплом и светом в домах, продуктами питания, транспортом, одеждой и т. Д. До настоящего времени во многих районах Сибири отсутствует централизованное энергоснабжение. Важной особенностью горных стран является большое рассредоточение потребителей электрической и тепловой энергии, неравномерная нагрузка в течение года и отсутствие централизованных источников энергии. Основным видом энергоисточников в горных районах являются дизельные электростанции. Стоимость получаемой энергии очень велика, особенно в отдалённых районах. Решение энергетической проблемы станет возможным лишь благодаря концепции освоения горных регионов с использованием возобновляемых источников энергии. В работе рассмотрены основные закономерности ветроэнергетического потенциала центральных районов Республики Алтай. Для выбора оптимального режима работы ветроэнергетических установок, исходя из мощности электрических нагрузок, а также данных, необходимых для конструирования, расчётов, оценки прочности требуются дополнительные исследования, в том числе микроклиматические наблюдения за ветровым режимом.

Цель: оценить возможный вклад энергии ветра в энергоэффективность и улучшение экологических условий в горных районах Республики Алтай при интенсивном развитии туристско-рекреационной деятельности.

Объекты: ветровой режим в нижней тропосфере над югом Сибири; орографические условия и их влияние на ветровой режим; ветроэнергетический потенциал среднегорных районов Республики Алтай.

Методы: температурно-ветровое зондирование атмосферы; построение математической модели поля скорости ветра в нижней тропосфере на различных высотных уровнях; оценка и анализ влияния различных форм рельефа на скорость ветра.

Результаты. Показано, что в условиях межгорных котловин и широких долин скорости ветра малы для развития ветроэнергетики. Анализ аэроклиматических показателей скорости ветра и данные высокогорных метеорологических станций на вершинах и водоразделах показали, что в условиях открытости горизонта ветроэнергетический потенциал достаточен для эффективной работы ветроэнергетических установок различной мощности. Для водораздельных участков выше 1500 м удельная мощность ветрового потока составляет от 150 до 850 Вт/м², что позволяет эксплуатировать ветроэнергетические установки малой и средней мощности. За зону большой энергетики могут быть приняты районы с удельной мощностью ветрового потока более 500 Bт/м². Такая зона может быть выделена в центральной части Горного Алтая, начиная примерно с 2200 м.
\end{abstract}

Ключевые слова:

Ветер, скорость ветра, энергоресурсы, ветроэнергетический потенциал, Алтай, ветроэнергетическая установка.

\section{Введение}

Экономическое развитие Республики Алтай предусматривает дальнейшее развитие промышленности, сельскохозяйственного производства, туризма, энергетики.

Главной задачей экономического развития должно быть сохранение благоприятных экологических условий природной среды. Основное внимание направлено на развитие рекреации и туризма в регионе, а также на развитие энергетической базы республики, поскольку до настоящего времени она остается энергодефицитной и предусматривает поступление энергии из соседних регионов. Главным направлением в развитии энергетики является использование возобновляемых источников энергии (ВИЭ). За короткое время построены мощные гелиоэнергетические станции в поселке Яйлю на Телецком озере, в районном центре Кош-Агач в Чуйской степи, в Усть-Канской степи, в селе Майма.

Существуют планы создания малых и микрогидроэлектростанций на горных реках.
Для горных территорий Алтая значительный интерес представляет оценка потенциальных ветроэнергетических ресурсов для выработки электрической энергии. Этот путь увеличения энергетического потенциала территории за счет ВИЭ является самым экономичным и экологически безвредным.

\section{Исходные материалы, методика исследований}

Для изучения ветрового режима были использованы данные многолетних наблюдений за скоростью ветра на сети метеорологических станций Росгидромета в Республике Алтай, справочники $[1,2]$, ежемесячники, данные ВНИИГМИ-МЦД. Были использованы материалы аэроклиматических справочников [3] и ежемесячников для характеристики ветрового режима в свободной атмосфере по данным сети аэрологических станций (Новосибирск, Семипалатинск, Красноярск, Хакасская, Кызыл, Барнаул). Численный анализ ветрового режима по многолетним данным аэрологи- 
ческих станций позволил получить математическую модель поля ветра (полином первой степени), что дает возможность оценить распределение его скорости в верхнем поясе гор: на водоразделах в разных частях склонов, в долинах и котловинах при отсутствии наземных метеорологических данных.

Для учета влияния на ветровой режим орографических условий учитывались морфологические характеристики рельефа: абсолютная и относительная высота склонов, их экспозиция по отношению к преобладающему ветровому потоку. С этой целью использовались географические карты рельефа и орографические схемы Республики Алтай.

\section{Результаты исследования}

Движения воздуха в атмосфере определяют огромные экологически чистые энергетические ресурсы [4-6]. Однако использование их в качестве источника энергии представляет сложную комплексную проблему [7-10], которая находится на стыке техники, экономики, метеорологии, экологии и других наук. Решением ее занимается ветроэнергетика, теоретические основы которой были заложены еще в начале прошлого века в период зарождения и быстрого развития авиации.

Для территории России и Сибири, в частности, выполнен ряд исследований по оценке ветроэнергетических ресурсов $[4,5,11]$. Во всех перечисленных работах горные районы Алтая оцениваются как совершенно неперспективные для развития ветроэнергетики, или их относят к малоисследованным с этой точки зрения районам. Такой вывод представляется закономерным, так как метеорологические станции, по данным которых оценивается ветроэнергетический потенциал, располагаются в основном в межгорных котловинах или в широких долинах, то есть в условиях с ослабленным воздухообменом. В табл. 1 приведены средние месячные скорости ветра в центральные месяцы сезонов года и средние годовые скорости ветра на станциях Горного Алтая, расположенных в горных котловинах. Станция Аккем расположена в высокогорной горноледниковой долине. Станция КараТюрек, самая высокогорная в России, располагается на водораздельном участке отрога Катунского хребта с высокой степенью открытости горизонта.

Более половины всех станций показывают среднюю годовую скорость ветра менее 2 м/с. Кроме того, следует учитывать, что в холодный период года, когда особенно остро встает вопрос об обеспечении энергией, над Сибирью располагается обширный сибирский антициклон, характеризующийся небольшими градиентами давления, мощной температурной инверсией и устойчивостью атмосферы. Все это сказывается на уменьшении скорости ветра, особенно у земной поверхности и, соответственно, на уменьшении ветроэнергетического потенциала.

На открытых высоких склонах и на водоразделах наблюдаются значительно большие скорости ветра. Примером могут служить данные на станции Кара-Тюрек (табл. 1). Относительно большие скорости ветра наблюдаются в долинах, где отмечается большая повторяемость местных воздушных течений: фёновых, ледниковых, горно-долинных ветров [6, 11].

Таблица 1. Средние месячные и годовые скорости ветра (м/с) $[1,2]$. Горный Алтай

Table 1. Average monthly and annual wind speed $(\mathrm{m} / \mathrm{s})[1,2]$. Gorny Altai

\begin{tabular}{|c|c|c|c|c|c|}
\hline \multirow{2}{*}{$\begin{array}{c}\text { Станция, высота над уровнем моря, м } \\
\text { Station, height above sea level, m }\end{array}$} & \multicolumn{4}{|c|}{ Месяц/Month } & \multirow{2}{*}{$\begin{array}{l}\text { Год } \\
\text { Year }\end{array}$} \\
\hline & I & IV & VII & $\mathrm{X}$ & \\
\hline Усть-Кан (Ust-Kan), 1037 & 2,4 & 3,2 & 2,6 & 2,9 & 2,8 \\
\hline Онгудай (Onguday), 832 & 0,5 & 1,8 & 1,3 & 1,0 & 1,1 \\
\hline Усть-Кокса (Ust-Koksa), 978 & 1,0 & 2,3 & 1,6 & 1,9 & 1,7 \\
\hline Катанда (Katanda), 900 & 1,5 & 2,1 & 1,6 & 1,8 & 1,8 \\
\hline Аккем (Akkem), 2050 & 2,0 & 2,9 & 2,1 & 2,7 & 2,4 \\
\hline Кара-Тюрек (Kara-Tyurek), 2600 & 6,6 & 6,2 & 4,3 & 7,7 & 6,2 \\
\hline
\end{tabular}

Для оценки ветроэнергетического потенциала верхнего пояса гор были использованы пространственно-временные характеристики поля ветра в нижней тропосфере над центральными районами Горного Алтая по аэроклиматическим данным [3]. Годовой ход скорости ветра в тропосфере над Алтаем можно проследить на рис. 1.

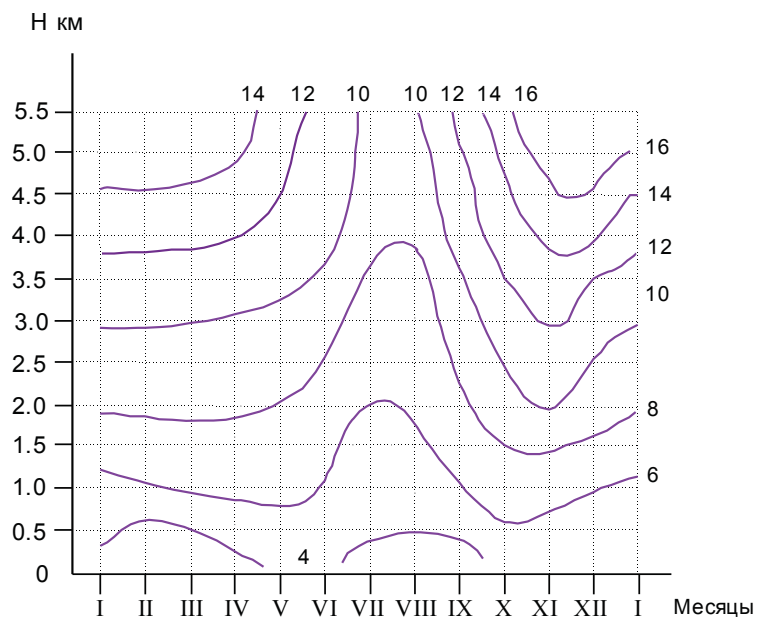

Puc. 1. Изотахи средней месячной скорости ветра $($ м/с) в ни жней тропосфере [12]. Центральный Алтай

Fig. 1. Isotaches of average monthly wind speed $(\mathrm{m} / \mathrm{s})$ in the lower troposphere [12]. Central Altai

Максимальные скорости ветра наблюдаются в переходные сезоны года, причем максимум в ноябре составляет на высоте $5000 \mathrm{~m} 17,7 \mathrm{~m} / \mathrm{c}$, а в апреле - лишь 15,6 м/с. Такие особенности прослеживаются и на ниже лежащих уровнях. Амплитуда годового хода скорости ветра с высотой резко увеличивается от $1 \mathrm{~m} / \mathrm{c}$ на высоте $500 \mathrm{~m}$ до $9 \mathrm{~m} / \mathrm{c}$ на высоте 5000 м. Увеличение амплитуды скорости ветра с высотой объясняется ослабеванием силы трения по мере удаления от подстилающей поверхности.

Ветры в условиях свободной атмосферы, как известно, достаточно близко характеризуют ветро- 
вой режим на вершинах, на открытых водораздельных участках. Однако полностью отождествлять данные по флюгеру на метеорологических станциях, находящихся на водоразделах, с условиями свободной атмосферы нельзя, так как шероховатость подстилающей поверхности заметно уменьшает скорость ветра.

Для количественной оценки влияния на скорость ветра подстилающей поверхности на водоразделах, на склонах различной ориентации по отношению к преобладающему направлению ветра, а также в долинах и котловинах проводилось сравнение данных фактических наблюдений с расчетными значениями скорости ветра [12].

Отношение скорости ветра по флюгеру к расчетной скорости характеризуется коэффициентом $K$.

$$
K=V_{\text {фл }} / V_{\text {расч }},
$$

где $V_{\text {фл }}$ - средняя месячная скорость ветра по флюгеру, м/c; $V_{\text {расч }}$ - средняя месячная скорость ветра расчётная, $\mathrm{M} / \mathrm{c}$.

Изменения в течение года коэффициента $K$, рассчитанного по формуле (1), на станциях, расположенных в верхнем поясе гор в условиях открытости горизонта в Алтае-Саянском регионе и на Кавказе, приведены на рис. 2.

Отношения фактических скоростей ветра к расчетным на высокогорных станциях, приведенные на рис. 2, изменяются в течение года очень незначительно. Это подтверждает высокую степень связности ветрового режима на высокогорных станциях с условиями свободной атмосферы.

Несколько большие значения коэффициента $K$ можно отметить в холодный период года. Близость значений коэффициента $K$ в разные месяцы позволяет использовать для станций единую среднюю годовую величину $K$. Значения коэффициента $K$ близки по своим значениям как на больших высотах (станция Кара-Тюрек, 2600 м), так и на вершинах в низкогорных и среднегорных районах (станция Северный поселок, 793 м). Данные по Кавказским станциям также подтверждают этот вывод.

На отдельных метеорологических станциях выделяются периоды со скоростью ветра, превышающей его значения в свободной атмосфере на том же уровне. Особенно это характерно для холодного периода года. Такие орографические условия вызывают большой интерес и требуют специальных анемометрических и аэрологических исследований. Можно предположить, что такие зоны с усилением ветра носят локальный характер и относятся лишь к узким зонам в районах перевалов, между горными проходами. Значительные усиления ветра относительно условий свободной атмосферы наблюдаются также в районах с очень интенсивным развитием фёнов.

Следует заметить, что для оценки влияния орографии, в частности склонов, могут быть использованы данные специальных микроклиматических наблюдений. Этим вопросам уделялось существенное внимание в работах [13-17]. Эти исследования относятся в основном к низкогорной или холмистой местности и к кратковременным периодам наблюдений. В этих работах приводятся поправочные коэффициенты на скорость ветра относительно скорости ветра на открытой равнинной местности.
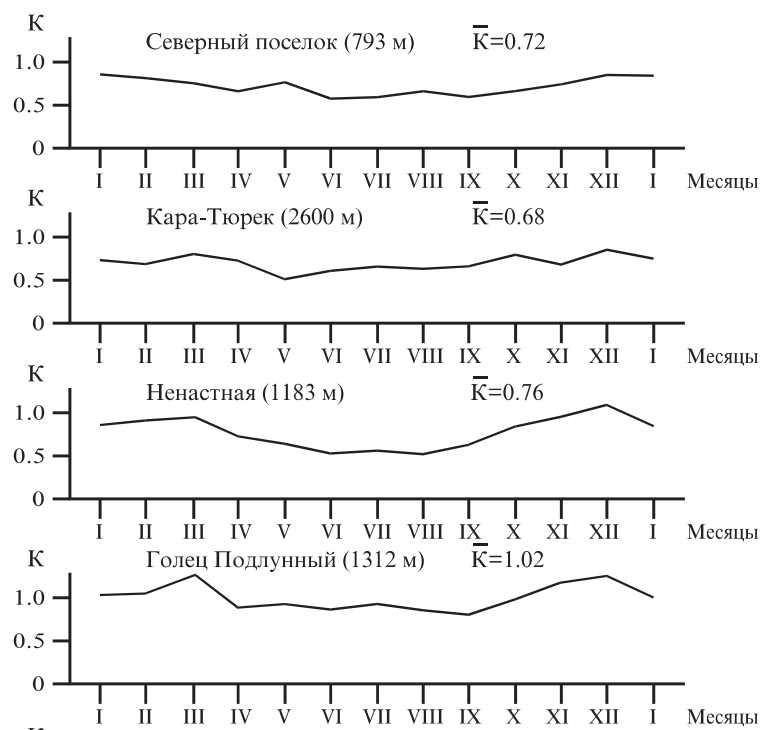

K Гагрский перевал (1644 м) $\quad \overline{\mathrm{K}}=0.53$

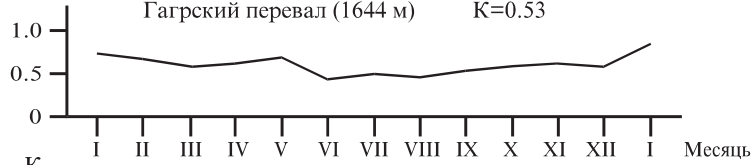
K Мамисоновский пер. $(2854$ м) $\quad \bar{K}=0.72$
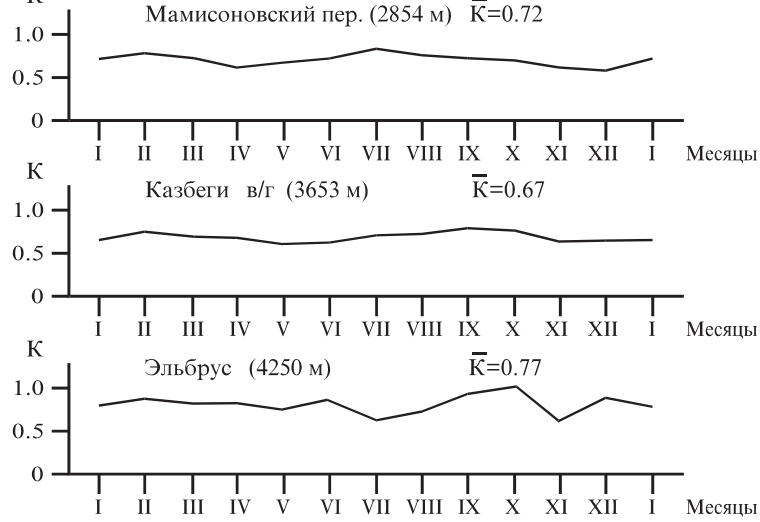

Puс. 2. Годовой ход коэффиииента К на вершинахи на водоразде$\operatorname{sax}$

Fig. 2. Annual variations of the coefficient $K$ on vertices and watersheds

Совместный анализ сведений, содержащихся в литературных источниках, и экспериментальных данных об изменчивости скорости ветра в различных формах рельефа позволяет определить коэффициенты уменьшения скорости ветра по сравнению со скоростью ветра в условиях свободной атмосферы на той же высоте над уровнем моря (табл. 2). Использование этих коэффициентов дает возможность оценить наиболее вероятные средние скорости ветра в местах, где не было наблюдений за ветровым режимом. 
Таблииа 2. Отношение (K) средней месячной скорости ветра на высоте флюгера в различных формах рельефа к скоро сти ветра в свободной атлосфере

Table 2. $\quad$ Ratio of the average monthly wind speed at the height of the vane in various forms of relief to the wind speed in the free atmosphere $(K)$

\begin{tabular}{|l|c|}
\hline \multicolumn{1}{|c|}{ Характеристика рельефа/Characteristics of the terrain } & $K$ \\
\hline Вершины и возвышенности/Tops and hill & 0,7 \\
\hline $\begin{array}{l}\text { Хорошо выраженный наветренный склон } \\
\text { Pronounced windward slope }\end{array}$ & $0,4-0,5$ \\
\hline Подветренный склон/Leeward slope & $0,3-0,4$ \\
\hline Склон, параллельный ветру/Slope parallel to wind & $0,4-0,5$ \\
\hline Горные долины поперечные/Mountain valley cross & 0,3 \\
\hline Горные долины продольные/Mountain valley longitudinal & $0,4-0,5$ \\
\hline Котловины/Depression & $0,2-0,3$ \\
\hline
\end{tabular}

Заметим, что приведенные коэффициенты $K$ являются осредненными за год и могут быть дифференцированы в зависимости от времени года. На открытых возвышенностях и на вершинах величина отношения $K$ в течение года практически не меняется.

Таким образом, определение средних месячных значений скорости ветра для оценки потенциальных ветроэнергетических ресурсов в Центральном Алтае на водораздельных участках, на склонах и в других орографических условиях возможно при использовании характеристик ветрового режима в нижней тропосфере. Средняя погрешность интерполяции скорости ветра на высоте 3000 м над уровнем моря на независимом материале над станцией Барнаул составила $0,3 \pm 0,2 \mathrm{м} / \mathrm{c}$ в тёплый период и $1,0 \pm 0,6 \mathrm{м} / \mathrm{c}$ в холодный период года.

Климатическую информацию, используемую для составления ветроэнергетического кадастра, можно подразделить на три вида.

К первому виду информации относятся климатические характеристики, используемые при оценке ветроэнергетического потенциала. Сюда входят: средняя многолетняя скорость ветра в целом за год и по месяцам, суточный ход скорости ветра в разные сезоны, повторяемость скорости ветра по градациям в разные сезоны или месяцы года, вертикальные профили скорости ветра, коэффициенты, учитывающие изменение скорости ветра в пространстве под влиянием макро- и мезонеоднородностей подстилающей поверхности.

Второй вид информации представляют данные, необходимые для выбора оптимального режима работы ветроэнергетических установок (ВЭУ). Это, прежде всего, сведения о непрерывной продолжительности скорости ветра выше заданного значения и о так называемых «энергетических затишьях», т. е. о скорости ветра ниже уровня, начиная с которого происходит реальная выработка электрической энергии (уровень определяется техническими особенностями ВЭУ).

К третьему виду климатической информации относятся климатические характеристики, необходимые для конструирования ВЭУ, т. е. для расчетов их прочности и устойчивости. Сюда входят: расчетная максимальная скорость ветра редкой повторяемости, данные о порывах ветра, параметрах турбулентности атмосферы в данном районе и другие характеристики.

На данном этапе исследований пойдет речь только о предварительной оценке ветроэнергетического потенциала верхнего пояса гор на территории Центрального Алтая. Аэроклиматическая информация не обеспечивает возможности получения подробных ветроэнергетических характеристик (мала частота зондирования атмосферы, получение некоторых показателей возможно лишь косвенными методами, например, максимальные порывы ветра, продолжительность периодов затиший и т. д.). Поэтому основная задача авторов привлечь внимание различных специалистов к оценке средних скоростей ветра в условиях орографической открытости и показать перспективность развития ветроэнергетики, поскольку этот показатель является одним из основных для оценки энергоресурсов.

В качестве примера приведем средние месячные скорости ветра в различных формах рельефа на разных высотах в Центральном Алтае (табл. 3).

таблииа 3. Средние месячные и годовые скорости ветра на водоразделах и на наветренных склонах, на разных высотах Теректинского, Семинского и Куминского хребтов. Центральный Алтай

Table 3. $\quad$ Average monthly and annual wind speed on watersheds and on the windward slopes, at different altitudes of Terektinsky, Seminsky and Kuminsky ranges. Central Altai

\begin{tabular}{|c|c|c|c|c|c|c|c|c|}
\hline \multirow{2}{*}{$\begin{array}{l}\text { Орографи- } \\
\text { ческие } \\
\text { условия } \\
\text { Orographic } \\
\text { conditions }\end{array}$} & \multirow{2}{*}{$\begin{array}{l}\text { Высота, м } \\
\text { Height, m }\end{array}$} & \multicolumn{4}{|c|}{$\begin{array}{l}\text { Месяц } \\
\text { Month }\end{array}$} & \multirow{2}{*}{ 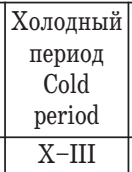 } & \multirow{2}{*}{$\begin{array}{c}\text { Tеплый } \\
\text { период } \\
\text { Warm } \\
\text { period } \\
\text { IV-IX }\end{array}$} & \multirow{2}{*}{ 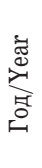 } \\
\hline & & I & IV & VII & $\mathrm{X}$ & & & \\
\hline \multirow{3}{*}{$\begin{array}{c}\text { Водоразделы } \\
\text { Watersheds }\end{array}$} & 1000 & 3,7 & 3,9 & 3,7 & 4,3 & 4,1 & 3,9 & 4,0 \\
\hline & 1500 & 4,3 & 4,5 & 3,8 & 5,1 & 4,8 & 4,1 & 4,5 \\
\hline & 3000 & 6,8 & 6,7 & 4,8 & 6,8 & 7,2 & 5,8 & 6,5 \\
\hline \multirow{3}{*}{$\begin{array}{c}\text { Наветренные } \\
\text { склоны } \\
\text { Windward } \\
\text { slopes }\end{array}$} & 1000 & 2,7 & 2,9 & 2,7 & 3,2 & 3,1 & 2,9 & 3,0 \\
\hline & 1500 & 3,2 & 3,3 & 2,8 & 3,6 & 3,5 & 3,0 & 3,3 \\
\hline & 3000 & 5,0 & 5,0 & 3,5 & 5,0 & 5,3 & 4,3 & 4,8 \\
\hline
\end{tabular}

В настоящее время условия экономически оправданной эксплуатации ВЭУ в зависимости от среднегодовой скорости ветра $\left(V_{c}\right)$ можно приближенно оценить следующим образом [11]:

- при $V_{c}<2,5-3 \mathrm{~m} / \mathrm{c}$ - бесперспективные;

- $\quad$ при $3 \leq V_{\mathrm{c}}<3,5$ м/с - малоперспективные;

- при 3,5 $\leq V_{c}<4,0$ м/c - перспективные для ВЭУ малой мощности;

- при $4 \leq V_{c}<5,5 \mathrm{~m} / \mathrm{c}$ - перспективные для малой и большой мощности;

- при $V_{\mathrm{c}} \geq 5,5 \mathrm{~m} / \mathrm{c}$ - перспективные для всех ВЭУ.

В табл. 4 представлено несколько ВЭУ малой мощности (до 30 кВт) и их основные технические характеристики. Они могут использоваться в индивидуальной жилой застройке, в том числе в фермерском хозяйстве.

Одним из важнейших показателей ветроэнергетических ресурсов является потенциальная удель- 
ная мощность ветрового потока, которая может быть рассчитана по одной из приближённых формул (2) [11],

$$
N_{\mathrm{e}}=1,16 \mathrm{~V}^{3},
$$

где $N_{\text {е }}$ - удельная мощность ветрового потока $\left(\mathrm{B} \mathrm{T} / \mathrm{м}^{2}\right) ; V$ - средняя скорость ветра, м/с.

Таблица 4. Технические характеристики ВЭУ (мощность до $30 \mathrm{\kappa Bm})$ [18]

Table 4. Technical characteristics of wind turbines (power up to $30 \mathrm{~kW}$ ) [18]

\begin{tabular}{|c|c|c|c|c|c|}
\hline $\begin{array}{c}\text { Марка } \\
\text { агрегата } \\
\text { Brand } \\
\text { Assembly }\end{array}$ & 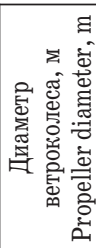 & 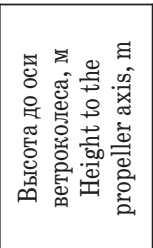 & 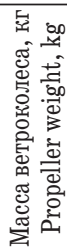 & 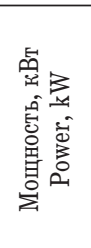 & 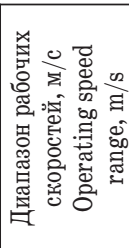 \\
\hline ВЭТУ-1,5 & $1,8-2,5$ & 4,$2 ; 7,2 ; 10,2$ & 150 & - & $5-40$ \\
\hline АВЭУ-0,3-2,4 & 2,4 & 6,0 & 165 & $0,6-0,7$ & $\geq 3$ \\
\hline ABЭ-2-4,5 & 4,5 & 8,3 & 600 & 2,2 & $4-40$ \\
\hline ВД-6 & 5,5 & 17,8 & 1500 & 3,0 & $\geq 3$ \\
\hline ВЭУ-10-10 & 10,0 & 11,6 & 2800 & 18,5 & - \\
\hline ЭСО-0020 & - & - & - & 20,0 & $\geq 5$ \\
\hline
\end{tabular}

Для размещения ВЭУ благоприятными являются следующие условия:

- высокий ветроэнергетический потенциал. В первом приближении его можно характеризовать величиной средней годовой скорости ветра $\bar{V}_{\text {с }} \geq 5 \mathrm{~m} / \mathrm{c}$ на высоте $10 \mathrm{м}$ (средняя высота флюгера или анеморумбометра) над подстилающей поверхностью;

- относительная продолжительность диапазона рабочих скоростей ветра составляет не менее 0,4 в течение сезона;

- район для размещения ВЭУ должен характеризоваться небольшой повторяемостью энергетических затиший, т. е. общая продолжительность периода со скоростью ветра менее $5 \mathrm{~m} / \mathrm{c}$ не должна превышать 20-30 \% ;

- небольшие значения коэффициента вариации скорости ветра.

Близкие к вышеизложенным условия в исследуемом районе могут наблюдаться лишь на водораздельных участках, на верхних участках наветренных склонов.

Практическое значение фоновых величин скорости ветра состоит в том, что они позволяют определить удельную мощность ВЭУ, расположенных на открытой местности, на водоразделах. Если в этом же районе можно разместить ВЭУ в более благоприятных орографических условиях (на вершинах или на верхней части наветренных склонов), то необходимо вводить поправки на увеличение удельной мощности. Максимумы удельной мощности ветра приурочены к переходным сезонам, основной минимум относится к летнему периоду и вторичный - к зимнему.

По аэроклиматическим данным о скорости ветра в свободной атмосфере были рассчитаны сред- ние месячные скорости ветра и удельная мощность для водораздельных участков на разных высотных уровнях для Центрального Алтая (табл. 5).

Различные высотные уровни водораздельных участков и наветренных склонов оценены по степени перспективности для размещения ВЭУ (табл. 6).

Таблица 5. Средние годовые характеристики ветроэнергетических ресурсов на водоразделах и наветренных склонах. Центральный Алтай

Table 5. Average annual characteristics of wind energy resources on watersheds and windward slopes. Central Altai

\begin{tabular}{|c|c|c|c|c|c|c|}
\hline $\begin{array}{c}\text { Орографичес- } \\
\text { кие условия } \\
\text { Orographic } \\
\text { conditions }\end{array}$ & $\begin{array}{l}\text { Высота, м } \\
\text { Height, m }\end{array}$ & $\begin{array}{l}\bar{V}_{\mathrm{c}} \\
\mathrm{M} / \mathrm{c} \\
\mathrm{m} / \mathrm{s}\end{array}$ & $\begin{array}{l}V_{\mathrm{pac}}, \\
\mathrm{M} / \mathrm{c} \\
\mathrm{m} / \mathrm{s}\end{array}$ & $F(v) \%$ & $\begin{array}{c}N_{\mathrm{e}} \\
\mathrm{BT} / \mathrm{M}^{2} \\
\mathrm{~W} / \mathrm{m}^{2}\end{array}$ & $\begin{array}{l}\text { Степень перспек } \\
\text { тивности, баллы } \\
\text { Prospects degree }\end{array}$ \\
\hline \multirow{4}{*}{$\begin{array}{c}\text { Водоразделы } \\
\text { Watersheds }\end{array}$} & 1500 & 4,6 & - & - & 113 & 2 \\
\hline & 2000 & 5,2 & - & - & 163 & 2 \\
\hline & 2500 & 5,8 & 53 & 58,7 & 263 & 1 \\
\hline & 3000 & 6,5 & - & - & 319 & 1 \\
\hline \multirow{4}{*}{$\begin{array}{c}\text { Наветренные } \\
\text { склоны } \\
\text { Windward } \\
\text { slopes }\end{array}$} & 1500 & 3,3 & - & - & 42 & 4 \\
\hline & 2000 & 3,7 & - & - & 59 & 3 \\
\hline & 2500 & 4,1 & - & - & 80 & 3 \\
\hline & 3000 & 4,5 & - & - & 102 & 3 \\
\hline
\end{tabular}

Примечание. Характеристика степени перспективности использования ВЭУ приведена в табл. 6. Здесь $\bar{V}_{\mathrm{c}}-$ средняя годовая скорость ветра; $V_{\text {расч }}$ - максимальная скорость ветра, возможная один раз в 10 лет; $F(v)$ - обеспеченность скорости ветра 3 м/ с и более; $N_{\mathrm{e}}$ - средняя удельная мощность ветрового потока.

Note: Characteristic of the degree of prospects for using wind turbines is shown in table 6 , where $\bar{V}_{\text {c }}$ is the average annual wind speed; $V_{\text {pac }}$ is the maximum wind speed, possible once every 10 years; $F(v)$ is the wind speed provision $3 \mathrm{~m} / \mathrm{s}$ or more; $N_{\mathrm{e}}$ is the average density power of the wind flow.

таблица 6. Характеристика степени перспективности терри тории для размещения ветроэнергетических уста новок

Table 6. $\quad$ Prospect degree of the site to accommodate wind turbines

\begin{tabular}{|c|c|c|c|}
\hline $\begin{array}{c}\text { Характеристика степени перспективности } \\
\text { Prospects degree }\end{array}$ & $\begin{array}{c}\bar{V}_{c}, \mathrm{M} / \mathrm{c} \\
\mathrm{m} / \mathrm{s}\end{array}$ & $\begin{array}{c}F(v) \\
\%\end{array}$ & $\begin{array}{c}N_{\mathrm{e}}, \mathrm{BT} / \mathrm{M}^{2} \\
\mathrm{~W} / \mathrm{m}^{2}\end{array}$ \\
\hline $\begin{array}{l}1 \text { балл. Перспективные в течение года } \\
1 \text { point. Perspective throughout the year }\end{array}$ & 4,0 & 55 & $200-1550$ \\
\hline $\begin{array}{l}2 \text { балла. Перспективные в определенные } \\
\text { сезоны года } \\
2 \text { points. Promising in certain seasons of } \\
\text { the year }\end{array}$ & $3,5-4,0$ & $45-55$ & $150-200$ \\
\hline $\begin{array}{l}3 \text { балла. Малоперспективные } \\
3 \text { points. Unpromising }\end{array}$ & $2,0-3,5$ & $25-45$ & $50-150$ \\
\hline $\begin{array}{l}4 \text { балла. Совершенно неперспективные } \\
4 \text { points. Absolutely unpromising }\end{array}$ & $\leq 2,0$ & $\leq 25$ & $\leq 50$ \\
\hline
\end{tabular}

Анализ скоростей ветра на открытых вершинах и водоразделах показывает, что в таких формах рельефа ветровой режим различается по сравнению с данными долинных и котловинных метеорологических станций.

Значительно выше средние скорости ветра, резко уменьшены амплитуды годового хода за счет увеличения скорости ветра на высотах в зимний период. Все это говорит о значительном увеличении потенциальных ветроэнергетических ресурсов верхнего пояса горных территорий. 
Для выбора оптимальных режимов работы ВЭУ одних только данных об удельной мощности ветрового потока недостаточно. К числу важнейших характеристик ветрового режима относится средняя непрерывная продолжительность скорости ветра выше (ниже) заданного значения $\tau_{\text {ср }}\left(V \geq V_{0}\right)$. В тех случаях, когда информация о скорости ветра ограничена одной лишь средней скоростью $V_{c}$, для расчета $\tau_{\text {ср }}\left(V \geq V_{0}\right)$ рекомендуется использовать косвенный метод расчёта непрерывной продолжительности скорости ветра выше заданного значения и энергетических затиший [11].

Для высокогорных районов Центрального Алтая средняя годовая повторяемость $V \geq 3 \mathrm{~m} / \mathrm{c}$ на высоте 1000 м составляет около 10 ч, на высоте 2000 м - 13,8 ч, на высоте 3000 м - 16,8 ч.

Строительство ВЭУ на водораздельных участках в отдалении от жилых поселков, производственных помещений, конечно, потребует дополнительных затрат на передачу электрической энергии, увеличатся и ее потери. Но с точки зрения экологической безопасности жизнедеятельности людей, наоборот, требуется относить ВЭУ как можно дальше, так как они создают определенный шум, от которого при нынешних технологиях еще не удается избавиться.

По данным о средних месячных скоростях ветра на водоразделах могут быть рассчитаны составные части ветроэнергетического кадастра. Важны такие характеристики, как повторяемость затиший и их продолжительность, вероятность рабочих скоростей ветра. Нижним пределом рабочей скорости для современных многолопастных тихоходных двигателей с учетом инновационных технологий является $2,5-3 \mathrm{~m} / \mathrm{c}$, а для быстроходных $4,5-5 \mathrm{~m} / \mathrm{c}$.

Годовая повторяемость скоростей ветра более $3 \mathrm{~m} /$ с составляет на водораздельных участках до $80 \%$ и более, а повторяемость скоростей ветра $5 \mathrm{~m} /$ с и более составляет до $50 \%$.

Удельная мощность ветрового потока зависит в большой мере от средних скоростей ветра, а следовательно, от местоположения и абсолютной высоты местности, а также от состояния устойчивости атмосферы. В центральной части Горного Алтая для водораздельных участков выше 1500 м над уровнем моря при скоростях ветра более $4 \mathrm{~m} / \mathrm{c}$ удельная мощность составляет от 150 до 850 Вт/ $\mathrm{M}^{2}$. Максимальная мощность может вырабатываться на высотах более 3000 м при обеспеченности скорости ветра более 3 м/с 45-60\% . Этот показатель определен Е.Н. Романовой [13] для Западного Алтая.

Как известно [19], за зону большой энергетики могут быть приняты районы с удельной мощностью более 500 Вт $/ \mathrm{m}^{2}$, при этом ВЭУ способны выдавать мощность до одного и более МВт, причем работа должна быть обеспечена в течение всего года. Такая зона может быть выделена в центральной части Горного Алтая, начиная примерно с 2200 м.

Зона малой ветроэнергетики - районы с удельной мощностью ветрового потока от 200 до
500 Вт/м². В таких условиях могут эксплуатироваться относительно небольшие ВЭУ мощностью 1-5 кВт. Продолжительность их эффективной работы 50-70 \% времени за год. Такие условия на Алтае возникают с высоты около 1500 м.

В данной работе мы не будем останавливаться на технических характеристиках ВЭУ различного типа. С ними можно познакомиться в ряде работ, в том числе в $[11,19]$. Отметим, что использование ВЭУ средней и малой мощности может оказаться наиболее рентабельным и способствовать достижению минимальной стоимости единицы производимой энергии.

Результаты расчетов показали, что неперспективными для размещения ВЭУ являются лишь котловины, подветренные склоны и узкие горные долины, ориентированные перпендикулярно господствующему направлению ветра, где средняя годовая скорость ветра менее 3 м/с. Эти районы характеризуются небольшими значениями средней годовой удельной мощностью ветрового потока менее 100 Вт/м², причем даже в периоды усиления ветра (весна, осень) удельная мощность ветрового потока в среднем редко превышает $150 \mathrm{BT} / \mathrm{m}^{2}$.

При оценке ветроэнергетических ресурсов в горных районах Алтая обязательно следует учитывать местные ветры. Для Горного Алтая характерны различные типы местных ветров: горно-долинные ветры, фёны, ледниковые ветры. Характеристики местных ветров на Алтае изложены в целом ряде работ автора [12 и др.] и здесь приводиться не будут. Отметим лишь, что для ветроэнергетики достаточно благоприятными являются фёны. В отдельных районах Горного Алтая имеются долины, отличающиеся большими скоростями ветра в холодный период, скорости ветра в них даже выше, чем в свободной атмосфере на том же уровне. Скорости ветра при фёнах больше, чем средние показатели, и при большой повторяемости фёны могут определять ветроэнергетический потенциал отдельных долин. Максимальная повторяемость фёнов, максимальные скорости ветра при фёнах наблюдаются в холодный период, именно тогда, когда наиболее велика потребность в энергии.

В долине Катуни (меридионально ориентированная ее часть), долине Чулышмана и в других районах наблюдается очень большое количество фёнов. Рельеф в таких долинах выполняет роль ветропроводящих коридоров [19] или воздуховодов, увеличивает скорость ветра. Из-за местного усиления ветра ВЭУ в таких районах могут успешно работать непосредственно на дне долины.

Менее благоприятными для ветроэнергетики являются горно-долинные ветры. Они на Алтае возникают лишь в тёплый период года. Для ветроэнергетики перспективными являются лишь периоды в суточном ходе, приходящиеся на вторую половину дня (14-18 ч). В период максимального развития долинного ветра скорости в среднем составляют 4-6 м/с. Горно-долинные ветры более интенсивны в открытых долинах. 
В соответствии с распределением скорости ветра в тропосфере наибольшими ветроэнергетическими ресурсами отличаются северные и западные районы Горного Алтая. По мере продвижения на юг и восток скорость ветра снижается вследствие роста расчленённости рельефа. Особенно быстро убывают средние значения скорости ветра к югу в холодный период - с октября по апрель, на $0,7-0,8 \mathrm{~m} / \mathrm{c}$ на $100 \mathrm{kм}$.

В целом можно сказать, что ветроэнергетические ресурсы Алтая на больших высотах весьма значительны и могут эффективно использоваться. Проведенное на независимом материале сравнение расчетных скоростей ветра с фактическими за отдельные месяцы по станции Кара-Тюрек показало, что разности не превышают 0,7 м/с, среднее квадратическое отклонение составляет в среднем $1,2 \mathrm{~m} / \mathrm{c}$.

Опыт применения аэроклиматических показателей для оценки ветроэнергетических ресурсов горных стран в условиях недостаточности метеорологической информации показал его перспективность, как в теоретическом, так и в прикладном отношении.

Использование ВИЭ является необходимой частью мероприятий для устойчивого развития общества и охраны окружающей среды. Они позволяют экономить органическое топливо, уменьшать объёмы его перевозок, при этом уменьшается поступление продуктов сгорания в атмосферу. В условиях низкого потенциала самоочищения атмосферы в условиях горных долин и котловин этот фактор имеет важнейшее значение для улучшения экологической обстановки.

Использование ВИЭ будет улучшать условия жизни людей, особенно в условиях разобщенности, будет способствовать сохранению лесов и уменьшению темпов деградации окружающей среды. Их использование может разрешить проблему снабжения электрической энергией большого числа мелких территориально разобщённых потребителей. При этом выровняется обеспеченность энергией районов с разной плотностью населения. Это приведёт к перестройке структуры энергопотребления и стиля жизни.

В современных условиях при отсутствии крупных инвестиций для создания энергетических объектов важным преимуществом ВИЭ является возможность ввода их в эксплуатацию в виде небольших модулей, не требующих больших капитальных вложений. Затем их можно наращивать по мере необходимости.

Перечисленные достоинства ВИЭ способны вызвать интерес к нетрадиционным источникам энергии, усиление научно-исследовательских разработок, совершенствование оборудования и снижение его стоимости.

Во многих публикациях ВИЭ характеризуются как абсолютно экологически чистые, не оказывающие негативного влияния на окружающую среду и человека. В связи с этим остановимся на некото- рых экологических аспектах этой проблемы и на сложностях осуществления планов широкого внедрения таких источников энергии.

Эксперты ООН начиная с 90-х гг. прошлого столетия анализировали состояние дел в этой отрасли энергетики и привлекали большое количество материалов по земному шару [20, 21]. Ими дана оценка экологических последствий использования различных видов нетрадиционных источников энергии. Общее заключение экспертов свидетельствует о том, что существующие представления о ВИЭ как о полностью экологически чистых источниках ошибочны [21]. Экспертиза показала необходимость анализа влияния ВИЭ на окружающую среду еще на стадии проектирования. Необходимо исследовать воздействие установок, связанных не только с выработкой энергии, но и с изготовлением оборудования, в том числе с добычей сырья для создания этого оборудования. Именно на этом этапе во многих случаях могут проявиться наиболее существенные отрицательные экологические воздействия на природу.

Установлено, что ВЭУ вызывают интенсивное акустическое излучение. Например, ветроустановка мощностью 2 МВт с лопастью пропеллера в 60 м (США, штат Каролина) отключается ночью из-за сильного шума [16]. Особую экологическую проблему представляют собой шумовые воздействия ВЭУ мощностью более 250 кВт. Замечено влияние работающих станций на прием теле- и радиопередач, отмечаются помехи для воздушного сообщения, изменяются показания навигационных приборов. ВЭУ травмируют и отпугивают птиц, особенно на перелетных трассах. При создании комплекса ВЭУ ухудшаются условия существования мелких наземных животных, птиц, насекомых. Для них нужны большие площади, и при этом они могут оказать влияние на изменение свойств почвенного покрова. Таким образом, необходим анализ воздействия источников энергии на окружающую среду ещё до стадии проектирования. Это позволит уменьшить неблагоприятные влияния на природу.

\section{Заключение}

1. В настоящее время вопросам использования возобновляемых источников энергии уделяется серьёзное внимание как во всем мире, так и в Республике Алтай. Эти источники энергии рассматриваются как существенное дополнение к традиционным. В Горном Алтае по масштабам ресурсов, экологической чистоте и повсеместной распространённости среди ВИЭ наиболее перспективна солнечная радиация. Недостатком ее является низкий уровень солнечной радиации в холодное время года, когда требуется максимальное количество энергии. Гелиоэнергетические ресурсы могут быть дополнены ветроэнергетическими ресурсами. Их максимальные значения в верхнем поясе гор достигают именно в холодный период года. 
2. Данные о ветровом режиме, полученные с помощью аэроклиматических показателей, позволили оценить потенциальные ветроэнергетические ресурсы Горного Алтая в верхнем поясе гор. Зона малой энергетики с удельной мощностью от 200 до $500 \mathrm{Bт} / \mathrm{m}^{2}$ располагается на наветренных склонах и водоразделах выше 1500 м над уровнем моря. Зона большой энергетики с удельной мощностью более $500 \mathrm{Bт} / \mathrm{m}^{2}$ выделена на наветренных склонах и водораздельных участках начиная с высоты 2200 м. При этом ВЭУ способны выдавать до 1 МВт/м². Неперспективными для размещения ВЭУ являются днища межгорных котловин, подветренные склоны и узкие горные долины, ориентированные перпендикулярно преобладающему направлению ветров. Таким образом, в верхнем поясе гор скорости ветра вполне достаточны, по крайней мере, для создания малой или средней ветроэнергетики, а на больших высотах возможна установка мощных ВЭУ, способных

\section{СПИСОК ЛИТЕРАТУРЫ}

1. Справочник по климату СССР: в 34 вып., в 5 ч. - Л.: Гидрометеоиздат, 1966. - Вып. 20. - Ч. ІІІ: Ветер. - 576 с.

2. Научно-прикладной справочник по климату СССР. Серия 3. Многолетние данные. - СПб.: Гидрометеоиздат, 1993. - 717 с.

3. Новый аэроклиматический справочник свободной атмосферы над СССР / под ред. И.Г. Гутермана. - М.: Гидрометеоиздат, 1979. - Т. 2. $-400 \mathrm{c}$

4. Дробышев А.Д. Энергия солнца и ветра в Краснодарском крае, условия ее утилизации. - СПб.: РГГМУ, 2016. - 276 с.

5. Карамов Д.Н. Формирование исходных метеорологических массивов с использованием многолетних рядов FM 12 Synop и METAR в системных энергетических исследованиях // Известия Томского политехнического университета. Инжиниринг георесурсов. - 2018. - Т. 329. - № 1. - С. 69-88.

6. Носкова Е.В., Обязов В.А. Изменения характеристик ветрового режима на территории Забайкальского края // Метеорология и климатология. - 2016. - № 7. - С. 29-36.

7. Troen I., Petersen E.L. European Wind Atlas. - Roskilde: Denmark-RISO National Laboratory, 1989. - $46 \mathrm{p}$.

8. Laapas M., Venäläinen A. Homogenization and trend analysis of monthly mean and maximum wind speed time series in Finland, 1959-2015 // International Journal of Climatology. - 2017. № 37. - P. 4803-4813.

9. Nchaba T., Mpholo M., Lennard C. Long-term austral summer wind speed trends over southern Africa // International Journal of Climatology. - 2017. - № 37. - P. 2850-2862.

10. Dadaser-Celik, Cengi. Wind speed trends over Turkey from 1975 to 2006 // International Journal of Climatology. - 2014. № 34. - P. 1913-1927.

11. Рекомендации по определению климатических характеристик ветроэнергетических ресурсов / под ред. 0.0. Штанниковой. Л.: Гидрометеоиздат, $1989 .-80$ с. обеспечить энергией туристические объекты, научные базы, альпинистские лагеря и т. д.

3. Эффективная работа ВЭУ возможна в отдельных горных долинах, где наблюдается большая повторяемость фёнов (южное побережье Телецкого озера, меридионально ориентированная часть долины Катуни, долина р. Чулышман и некоторые другие местности).

4. Использование ВИЭ является необходимой частью мероприятий для дальнейшего социально-экономического развития общества, особенно в условиях низкого потенциала самоочищения атмосферы в горных районах Сибири. Их использование приведет к выравниванию энергообеспеченности районов с разной плотностью населения. Важна возможность постепенного создания энергетических объектов, так как их можно вводить в эксплуатацию в виде отдельных модулей. Всё это постепенно приведёт к перестройке структуры энергопотребления и стиля жизни населения.

12. Севастьянов В.В. Климатические ресурсы Горного Алтая и их прикладное использование. - Томск: Изд-во ТГПУ, 2009. $252 \mathrm{c.}$

13. Романова Е.Н. Изменение климатических характеристик ветроэнергетических ресурсов под влиянием неоднородностей подстилающей поверхности // Рекомендации по определению климатических характеристик ветроэнергетических ресурсов / под ред. 0.0. Штанниковой. - Л.: Гидрометеоиздат, 1989. C. $25-51$.

14. Windatlas for Denmark-RISO / E.L. Petersen, I. Troen, S. Prandsen, K. Hedegaard. - Roskilde: Denmark-RISO National Laboratory, 1981. $-229 \mathrm{p}$.

15. Stewart D.A., Essenwanger 0.M. Frequecy distribution of wind speed near the surface // Journal of Applied Meteorology and Climatology. - 1978. - V. 17. - № 11. - P. 1633-1642.

16. Wieringa J. Roughness-dependent geographical interpolation of surface wind speed averages / / Quarterly Journal Royal Meteorological Society. - 1986. - V. 112. - № 473. - P. 867-889.

17. Carrol D.D. The wind resource at Altamont Pass // Sunworld. 1984. - V. 8. - P. 109-110.

18. Де Рензо Л. Ветроэнергетика. - М.: Энергоатомиздат, 1982. $271 \mathrm{c.}$

19. Сидорович В. Мировая энергетическая революция. Как возобновляемые источники энергии изменят наш мир. - М.: Альпина Паблишер, 2015. - 208 c.

20. Wind energy around the world // World Wind Energy Association Quarterly Bulletin. - 2015. - V. 1. - 54 p.

21. Балабанов М.С., Бабошкина С.В., Хамитов Р.Н. Экологические аспекты в энергосберегающей политике на этапе создания в России интеллектуальных энергосистем с активно-адаптивной сетью // Известия Томского политехнического университета. Инжиниринг георесурсов. - 2015. - Т. 326. - № 11. - С. 141-152.

Поступила 30.05.2018 г.

\section{Информация об авторах}

Севастьянов В.В., доктор географических наук, профессор кафедры метеорологии и климатологии геологогеографического факультета Национального исследовательского Томского государственного университета.

Canbян E.C., ассистент, старший лаборант, соискатель кафедры краеведения и туризма геолого-географического факультета Национального исследовательского Томского государственного университета. 


\title{
WINDPOWER RESOURCES OF CENTRAL REGIONS OF THE ALTAI REPUBLIC
}

\author{
Vladimir V. Sevastyanov', \\ vvs187@mail.ru \\ Ekaterina S. Sapian', \\ Katerinass@vtomske.ru \\ 1 Tomsk National Research State University, \\ 36, Lenin Avenue, Tomsk, 634050, Russia.
}

\begin{abstract}
The relevance. Among the most urgent problems attracting human interest are the problems of energy. They affect directly or indirectly on human society and the environment. The human activity is associated with permanent use of natural energy resources for supplying people with vital functions: heat and light in houses, food, transportation, clothes, etc. At present, in many parts of siberia there is still no centralized energy service. An important feature of mountainous countries is considerable dispersion of consumers requiring electric and thermal energy, uneven workload during the year and the lack of centralized sources of energy. The main energy sources in mountainous areas are diesel power plants. The cost of the energy produced is very high, particularly in remote areas. Due to the concept of mountain regions development with using renewable energy sources it is possible to solve the energy problem.

The aim of the research is to evaluate the possible contribution of wind energy to resource conservation and ecology in mountains regions of the Altai Republic in the frames of intensive development of tourism and recreational activities.

The objects of the research are the wind regime in lower troposphere over the southern part of Siberia; orographic conditions and their influence on the wind regime; wind-power potential of mountain areas of the Altai Republic

The methods of the research are the upper-air atmosphere sounding; the construction of a mathematical model of the wind velocity field in different altitude levels; assessment and analysis of influence of different topography on wind speed.

Results. It is shown that the wind velocity is not enough for wind-power engineering in conditions of intermountain basins and wide valleys. The analysis of air-climatological indicators of wind velocity and the data of high-mountain meteorological stations on the tops and watersheds have shown that in terms of openness of the horizon the wind-power potential is sufficient for effective operation of wind power plants of different capacity. For the watershed areas higher than $1500 \mathrm{~m}$, the power density fluctuates from 150 to $850 \mathrm{~W} / \mathrm{m}^{2}$ that makes it possible to use wind energy plants of low and medium power. The regions with wind power density of more than $500 \mathrm{~W} / \mathrm{m}^{2}$ can be considered as the areas of high energy. Such zones can be marked in the central part of the Altai Mountains, rising from $2200 \mathrm{~m}$.
\end{abstract}

Key words:

Wind, wind velocity, energy, wind energy potential, Altai, wind turbine

\section{REFERENCES}

1. Spravochnik po klimatu SSSR [Reference book on the USSR climate]. Vol. 20. P. III: Wind. Leningrad, Gidrometeoizdat Publ., 1966. $576 \mathrm{p}$.

2. Nauchno-prikladnoy spravochnik po klimatu SSSR [Scientific-applied reference book on the USSR climate]. Series 3. Long-term data. St-Petersburg, Gidrometeoizdat Publ., 1993.717 p.

3. Novy aeroklimaticheskiy spravochnik suobodnoy atmosfery nad SSSR [New aeroclimatic reference book of free atmosphere over the USSR]. Vol. 2. Moscow, Gidrometeoizdat Publ., 1979. 400 p.

4. Drobyshev A.D. Energiya solntsa i vetra $v$ Krasnodarskom krae, usloviya ee utilizatsii [Sun and wind energy in Krasnodar region, conditions of its disposal]. St-Petersburg, RGGMU Publ., 2016. $276 \mathrm{p}$.

5. Karamov D.N. Formation of initial meteorological massifs using multi-year series FM 12 Synop and METAR in system energy studies. Bulletin of the Tomsk Polytechnic University. Geo Assets Engineering, 2018, vol. 329, no. 1, pp. 69-88. In Rus.

6. Noskova E.V., Obyazov V.A. Changes in characteristics of wind regime in the Trans-Baikal Territory. Meteorology and Climatology, 2016, no. 7, pp. 29-36. In Rus.

7. Troen I., Petersen E.L. European Wind Atlas. Roskilde, Denmark-RISO National Laboratory, 1989. 46 p.

8. Laapas M., Venäläinen A. Homogenization and trend analysis of monthly mean and maximum wind speed time series in Finland, 1959-2015. International Journal of Climatology, 2017. no. 37, pp. 4803-4813.
9. Nchaba T., Mpholo M., Lennard C. Long-term austral summer wind speed trends over southern Africa. International Journal of Climatology, 2017, no. 37, pp. 2850-2862.

10. Dadaser-Celik and Cengi. Wind speed trends over Turkey from 1975 to 2006. International Journal of Climatology, 2014, no. 34, pp. 1913-1927.

11. Rekomendatsii po opredeleniyu klimaticheskikh kharakteristik vetroenergeticheskikh resursov [Guidelines on determining the climatic characteristics of wind energy resources]. Leningrad, Gidrometeoizdat Publ., 1989.80 p.

12. Sevastyanov V.V. Klimaticheskie resursy Gornogo Altaya i ikh prikladnoe ispolzovanie [Climate resources of the Altai mountains and their applications]. Tomsk, Tomsk State Pedagogical University Publ., 2009. 252 p.

13. Romanova E.N. Izmenenie klimaticheskikh kharakteristik vetroenergeticheskikh resursov pod vliyaniem neodnorodnostey podstilayushchey poverkhnosti [Changes in climatic characteristics of wind energy resources under the influence of inhomogeneities of the underlying surface]. Rekomendatsii po opredeleniyu klimaticheskikh kharakteristik vetroenergeticheskikh resursov [Guidelines on determining the climatic characteristics of wind energy resources]. Leningrad, Gidrometeoizdat Publ., 1989. pp. 25-51.

14. Petersen E.L., Troen I., Prandsen S., Hedegaard K. Windatlas for Denmark-RISO. Roskilde, Denmark-RISO National Laboratory, 1981. $229 \mathrm{p}$.

15. Stewart D.A., Essenwanger 0.M. Frequency distribution of wind speed near the surface. Journal of Applied Meteorology and Climatology, 1978, vol. 17, no. 11, pp. 1633-1642. 
16. Wieringa J. Roughness-dependent geographical interpolation of surface wind speed averages. Quarterly Journal Royal Meteorological Society, 1986, vol. 112, no. 473, pp. 867-889.

17. Carrol D.D. The wind resource at Altamont Pass. Sunworld, 1984, vol. 8, pp. 109-110.

18. De Renzo L. Vetroenergetika [Wind Energy]. Moscow, Energoatomizdat Publ., 1982. $271 \mathrm{p}$.

19. Sidorovich V. Mirovaya energeticheskaya revolyutsiya. Kak vozobnovlyaemye istochniki energii izmenyat nash mir [Global energy revolution. How renewable energy will change our world]. Moscow, Alpina Publ., 2015. 208 p.
20. Wind energy around the world. World Wind Energy Association Quarterly Bulletin, 2015, vol. 1, $54 \mathrm{p}$.

21. Balabanov M.S., Baboshkina S.V., Khamitov R.N. Electric saving and environmental aspects in policy at the stage of smart grid creation in Russia. Bulletin of the Tomsk Polytechnic University. Geo Assets Engineering, 2015, vol. 326, no. 11, pp. 141-152. In Rus.

\section{Information about the authors}

Vladimir V. Sevastyanov, Dr. Sc., professor, Tomsk National Research State University.

Ekaterina S. Sapian, assistant, Tomsk National Research State University. 